\title{
A RMRAC Parameter Identification Algorithm Applied to Induction Machines
}

\author{
Rodrigo Z. Azzolin ${ }^{1}$, Cristiane C. Gastaldini ${ }^{2}$, Rodrigo P. Vieira ${ }^{3}$ and \\ Hilton A. Gründling ${ }^{4}$ \\ 1,2,3,4 Federal University of Santa Maria \\ ${ }^{1}$ Federal University of Rio Grande \\ ${ }^{3}$ Federal University of Pampa \\ Brazil
}

\section{Introduction}

This chapter deals with the problem of parameter identification of electrical machines to achieve good performance of a control system. The development of an identification algorithm is presented, which in this case is applied to Single-Phase Induction Motors, but could easily be applied to other electrical machine. This scheme is based on a Robust Model Reference Adaptive Controller and measurements of stator currents of a machine with standstill rotor. From the obtained parameters, it is possible to design high performance controllers and sensorless control for induction motors.

Single-phase induction motors (SPIM) are widely used in fractional and sub-fractional horsepower applications, usually in locations where only single-phase energy supply is available. In most of these applications the machine operates at constant frequency and is fed directly from the AC grid with an ON/OFF starting procedure. In recent years, several researchers have shown that the variable speed operation can enhance the SPIM's efficiency (Blaabjerg et al., 2004; Donlon et al., 2002). In addition, other researchers have developed high performance drives for SPIM's, using Field-Oriented Control (FOC) and sensorless techniques (de Rossiter Correa et al., 2000; Vaez-Zadeh \& Reicy, 2005; Vieira et al., 2009b). However, the FOC associated with the sensorless technique demands accurate knowledge of electrical motor parameters to achieve good performance.

A good deal of research has been carried out in the last several years on parameter estimation of induction motors, mainly with regards to three-phase induction machines (Azzolin et al., 2007; Koubaa, 2004; Ribeiro et al., 1995; Velez-Reyes et al., 1989).

However, few methods have been proposed for automatic estimation in single-phase induction motors. One of them uses a classical method for electrical parameter identification (Ojo \& Omozusi, 2001), its implementation is onerous. In (Vieira et al., 2009a) a Recursive Least Squares (RLS) identification algorithm is used to obtain machine parameters. The identification results are good, although this method requires the design of filters to obtain the variable derivative, which can be deteriorated by noises.

In order to solve these problems, this chapter details a closed-loop algorithm to estimate the electrical parameters of a single-phase induction motor based on (Azzolin \& Gründling, 


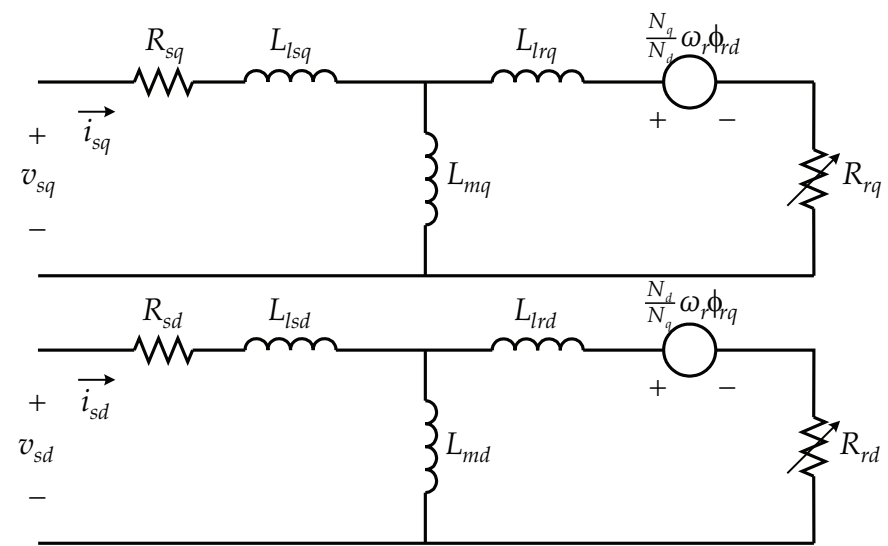

Fig. 1. Equivalent circuit of a SPIM.

2009). In (Azzolin \& Gründling, 2009) a Robust Model Reference Adaptive Controller (RMRAC) algorithm was used for parameter identification of three-phase induction motors. The RMRAC algorithm eliminates the use of filters to obtain derivatives of the signals. Thus, the objectives of this chapter are to apply the RMRAC algorithm in the electrical parameter identification of a SPIM and make use of the robustness of the system in dealing with of noise measurement.

As a result, the proposed parameter estimation procedure is divided into three steps:

(I) identification of the RMRAC controller gains;

(II) estimation of the transfer function coefficients of the induction motor at standstill;

(III) calculation of the stator resistance $R_{s i}$, rotor resistance $R_{r i}$, stator inductance $L_{s i}$, rotor inductance $L_{r i}$ and mutual inductance $L_{m i}$ using steps (I) and (II), where the index " $i$ " express the axes $\mathrm{q}$ or $\mathrm{d}$.

This chapter is organized as follows: Section 2 presents the induction machine model. A short review of the RMRAC algorithm applied to the identification system is presented in sections 3 and 4 . Section 5 describes the assumptions and equations of Model Reference Control (MRC) while section 6 shows the proposed parameter identification algorithm. Sections 7 and 8 present the simulation and experimental results. Finally, chapter conclusions are presented in section 9 .

\section{Mathematical model of a single phase induction motor}

The SPIM equivalent circuit without the permanent split-capacitor can be represented by an asymmetrical two-phase induction motor as shown in Fig. 1 . In this figure $L_{l s i}$ and $L_{l r i}$ are the stator and rotor leakage inductances, $\omega_{r}$ is the speed rotor, $\phi_{r i}$ is the electromagnetic flux and $N_{i}$ is the number of turns for auxiliary winding or axis $\mathrm{d}$ and for main winding or axis $\mathrm{q}$. The stator and rotor inductances are relationship with the leakage and mutual inductance as a $L_{s i}=L_{l s i}+L_{m i}$ and $L_{r i}=L_{l r i}+L_{m i}$, respectively.

From Fig. 1 and from (Krause et al., 1986) it is possible to derive the dynamical model of a SPIM. The SPIM dynamical model in a stationary reference frame can be described by 1 . In this 
equation $\bar{\sigma}_{q}=L_{s q} L_{r q}-L_{m q}^{2}, \bar{\sigma}_{d}=L_{s d} L_{r d}-L_{m d^{\prime}}^{2} p$ is the poles pairs and $n$ is the relationship between the number of turns for auxiliary and for main winding $N_{d} / N_{q}$.

$$
\begin{array}{r}
\left.\cdot \begin{array}{l}
\dot{i_{s q}} \\
i_{s d} \\
i_{r q} \\
i_{r d}
\end{array}\right]=\left[\begin{array}{cccc}
-\frac{R_{s q} L_{r q}}{\bar{\sigma}_{q}} & -p \omega_{r} \frac{1}{n} \frac{L_{m q} L_{m d}}{\bar{\sigma}_{q}} & \frac{R_{r q} L_{m q}}{\bar{\sigma}_{q}} & -p \omega_{r} \frac{1}{n} \frac{L_{r d} L_{m q}}{\bar{\sigma}_{q}} \\
p \omega_{r} n \frac{L_{m q} L_{m d}}{\bar{\sigma}_{d}} & -\frac{L_{r d} R_{s d}}{\bar{\sigma}_{d}} & p \omega_{r} n \frac{L_{r q} L_{m d}}{\bar{\sigma}_{d}} & \frac{R_{r d} L_{m d}}{\bar{\sigma}_{d}} \\
\frac{L_{m q} R_{s q}}{\bar{\sigma}_{q}} & p \omega_{r} \frac{1}{n} \frac{L_{s q} L_{m d}}{\bar{\sigma}_{q}} & -\frac{L_{s q} R_{r q}}{\bar{\sigma}_{q}} & p \omega_{r} \frac{1}{n} \frac{L_{s q} L_{r d}}{\bar{\sigma}_{q}} \\
-p \omega_{r} n \frac{L_{s d} L_{m q}}{\bar{\sigma}_{d}} & \frac{L_{m d} R_{s d}}{\bar{\sigma}_{d}} & -p \omega_{r} n \frac{L_{s d} L_{r q}}{\bar{\sigma}_{d}} & -\frac{L_{s d} R_{r d}}{\bar{\sigma}_{d}}
\end{array}\right] \\
\\
\cdot\left[\begin{array}{c}
i_{s q} \\
i_{s d} \\
i_{r q} \\
i_{r d}
\end{array}\right]+\left[\begin{array}{cc}
\frac{L_{r q}}{\bar{\sigma}_{q}} & 0 \\
0 & \frac{L_{r d}}{\bar{\sigma}_{d}} \\
-\frac{L_{m q}}{\bar{\sigma}_{q}} & 0 \\
0 & -\frac{L_{m d}}{\bar{\sigma}_{d}}
\end{array}\right]\left[\begin{array}{c}
v_{s q} \\
v_{s d}
\end{array}\right]
\end{array}
$$

From equation 1 it is possible to obtain the transfer functions in the axes $\mathrm{q}$ and $\mathrm{d}$ at standstill rotor $\left(\omega_{r}=0\right)$, where these equations are decoupled and presented in 2 and 3 .

$$
\begin{aligned}
& H_{q}(s)=\frac{i_{s q}(s)}{v_{s q}(s)}=\frac{s \frac{L_{r q}}{\bar{\sigma}_{q}}+\frac{R_{r q}}{\bar{\sigma}_{q}}}{s^{2}+s p_{q}+\frac{R_{r q} R_{s q}}{\bar{\sigma}_{q}}}, \\
& H_{d}(s)=\frac{i_{s d}(s)}{v_{s d}(s)}=\frac{s \frac{L_{r d}}{\bar{\sigma}_{d}}+\frac{R_{r d}}{\bar{\sigma}_{d}}}{s^{2}+s p_{d}+\frac{R_{r d} R_{s d}}{\bar{\sigma}_{d}}},
\end{aligned}
$$

where

$$
p_{q}=\frac{R_{s q} L_{r q}+R_{r q} L_{s q}}{\bar{\sigma}_{q}} \text { and } p_{d}=\frac{R_{s d} L_{r d}+R_{r d} L_{s d}}{\bar{\sigma}_{d}} .
$$

\section{Identification system}

The proposed electrical parameter identification system is shown in Fig. 2. This system is based on a RMRAC algorithm used to generate the control action $v_{s q}$ by the difference between the measured current $i_{s q}$ and the reference $i_{s q}^{*}$ at standstill rotor. In this test the auxiliary winding (or axis d) is open while the main winding (or axis q) is identified.

The dotted box in Fig. 2 is detailed in Fig. 3 where the RMRAC control law applied to q axis is shown. In Fig. 3, the reference model and plant are given by

$$
W_{m}(s)=k_{m} \frac{Z_{m}(s)}{R_{m}(s)}
$$




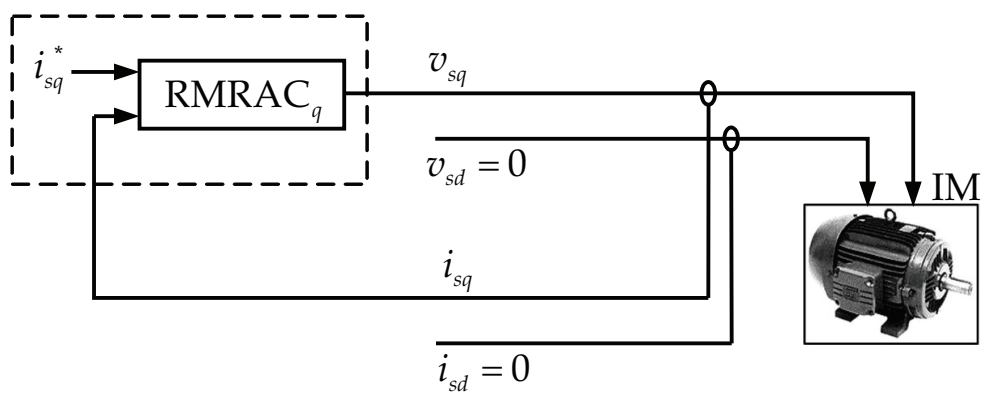

Fig. 2. Block diagram of the RMRAC identification system.

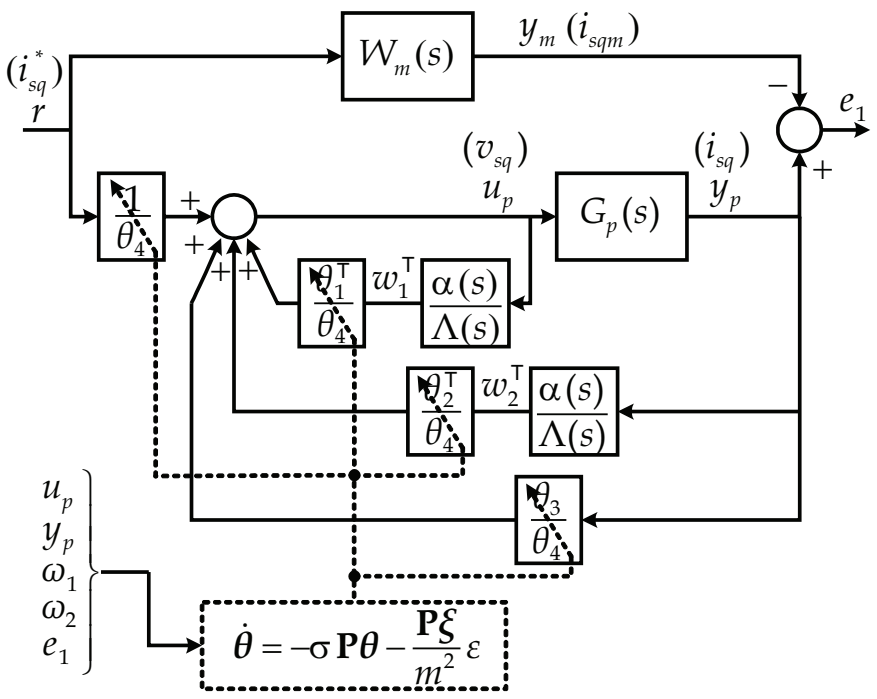

Fig. 3. RMRAC structure.

$$
G_{p}(s)=k_{p} \frac{Z_{p}(s)}{R_{p}(s)} .
$$

where $Z_{m}(s), R_{m}(s), Z_{p}(s)$ and $R_{p}(s)$ are monic polynomials and $k_{m}$ and $k_{p}$ are high frequency gains.

The general idea behind RMRAC is to create a closed-loop controller with gains that can be updated and change the response of the system. The output of the system $y_{p}$ is compared to a desired response from a reference model $y_{m}$. The controller gains vector $\boldsymbol{\theta}=\left[\begin{array}{llll}\theta_{1}^{\top} & \theta_{2}^{\top} & \theta_{3} & \theta_{4}\end{array}\right]^{\top}$ is updated by a gradient algorithm based on $e_{1}$ error. The goal is that the gains converge to ideal values that cause the plant response to match the response of the reference model. These gains can be obtained by a gradient algorithm presented in (Ioannou \& Sun, 1996; Ioannou \& Tsakalis, 1986) and described as follows. More details of RMRAC algorithms can be seen in (Câmara \& Gründling, 2004). 
The procedure described in Fig. 2 and Fig. 3 is applied to parameter identification of the q axis or transfer function 2. However, the same procedure is used for parameter identification of the $\mathrm{d}$ axis or transfer function 3.

\section{RMRAC gains adaptation algorithm}

The gradient algorithm used to obtain the control law gains is given by

$$
\dot{\boldsymbol{\theta}}=-\sigma \mathbf{P} \boldsymbol{\theta}-\frac{\mathbf{P} \xi}{m^{2}} \varepsilon
$$

with

$$
\dot{m}=\delta_{0} m+\delta_{1}\left(\left|u_{p}\right|+\left|y_{p}\right|+1\right), m(0)>\frac{\delta_{1}}{\delta_{0}}, \delta_{1} \geq 1,
$$

and

$$
\begin{gathered}
\boldsymbol{\xi}=W_{m}(s) \mathbf{I} \boldsymbol{w}, \\
w=\left[\begin{array}{llll}
w_{1}^{\top} & w_{2}^{\top} & y_{p} & u_{p}
\end{array}\right]^{\top},
\end{gathered}
$$

$w_{1}^{\top}, w_{2}^{\top}$ are auxiliary vectors, $\delta_{0}, \delta_{1}$ are positive constants and $\delta_{0}$ satisfies $\delta_{0}+\delta_{2} \leq \min \left(p_{0}, q_{0}\right)$, $q_{0} \in \Re^{+}$is such that the $W_{m}\left(s-q_{0}\right)$ poles and the $\left(\mathbf{F}-q_{0} \mathbf{I}\right)$ eigenvalues are stable and $\delta_{2}$ is a positive constant. The sigma modification $\sigma$ in 7 is given by

$$
\sigma=\left\{\begin{array}{clc}
0 & \text { if } \quad\|\boldsymbol{\theta}\|<M_{0} \\
\sigma_{0}\left(\frac{\|\boldsymbol{\theta}\|}{M_{0}}-1\right) & \text { if } M_{0} \leq\|\boldsymbol{\theta}\|<2 M_{0} \\
\sigma_{0} & \text { if } \quad\|\boldsymbol{\theta}\| \geq 2 M_{0}
\end{array}\right.
$$

where $M_{0}>\left\|\boldsymbol{\theta}^{*}\right\|$ and $\sigma_{0}>2 \mu^{-2} / R^{2}, R, \mu \in \Re^{+}$are design parameters. In this case, the parameters used in the implementation of the gradient algorithm are

$$
\left\{\begin{array}{l}
\delta_{0}=0.7 \\
\delta_{1}=1 \\
\delta_{2}=1 \\
\sigma_{0}=0.1 \\
M_{0}=10
\end{array},\right.
$$

More details of design of the gradient algorithm can be seen in (Ioannou \& Tsakalis, 1986). As defined in (Lozano-Leal et al., 1990), the modified error in 7 is given by

$$
\varepsilon=e_{1}+\boldsymbol{\theta}^{\top} \boldsymbol{\xi}-W_{m} \boldsymbol{\theta}^{\top} \boldsymbol{w}
$$

or

$$
\varepsilon=\phi^{\top} \xi+\mu \eta
$$

When the ideal values of gains are identified and the plant model is well known, the plant can be obtained by equation analysis of MRC algorithm described in the next section. 


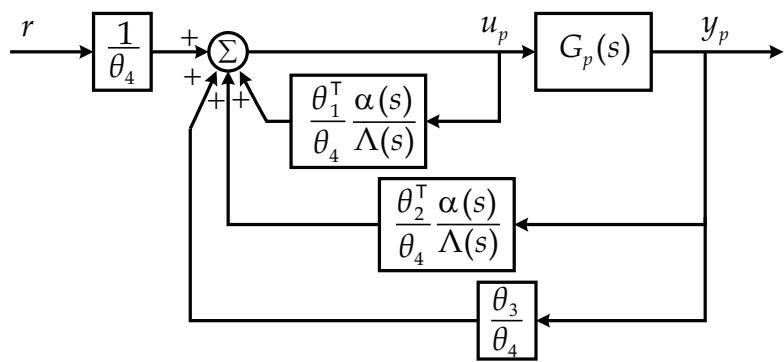

Fig. 4. MRC structure.

\section{MRC analysis}

The Model Reference Control (MRC) shown in Fig. 4 can be understood as a particular case of RMRAC structure, which is presented in Fig. 3. This occurs after the convergence of the controller gains when the gradient algorithm changes to the steady-state. It is important to note that this analysis is only valid when the plant model is well known and free of unmodeled dynamics and parametric variations.

To allow the analysis of the MRC structure, the plant and reference model must satisfy some assumptions as verified in (Ioannou \& Sun, 1996). These suppositions, which are also valid for RMRAC, are given as follow:

Plant Assumptions:

P1. $Z_{p}(s)$ is a monic Hurwitz polynomial of degree $m_{p}$;

P2. An upper bound $n$ of the degree $n_{p}$ of $R_{p}(s)$;

P3. The relative degree $n^{*}=n_{p}-m_{p}$ of $G_{p}(s)$;

$\mathbf{P 4}$. The signal of the high frequency gain $k_{p}$ is known.

Reference Model Assumptions:

M1. $Z_{m}(s), R_{m}(s)$ are monic Hurwitz polynomials of degree $q_{m}, p_{m}$, respectively, where $p_{m} \leq n$;

M2. The relative degree $n_{m}^{*}=p_{m}-q_{m}$ of $W_{m}(s)$ is the same as that of $G_{p}(s)$, i.e., $n_{m}^{*}=n^{*}$.

In Fig. 4 the feedback control law is

$$
u_{p}=\frac{\theta_{1}^{\top}}{\theta_{4}} \frac{\alpha(s)}{\Lambda(s)} u_{p}+\frac{\theta_{2}^{\top}}{\theta_{4}} \frac{\alpha(s)}{\Lambda(s)} y_{p}+\frac{\theta_{3}}{\theta_{4}} y_{p}+\frac{1}{\theta_{4}} r
$$

and

$$
\begin{array}{ll}
\alpha(s) \triangleq \alpha_{n-2}(s)=\left[s^{n-2}, s^{n-3}, \ldots, s, 1\right]^{\top} & \text { for } n \geq 2, \\
\alpha(s) \triangleq 0 & \text { for } n=1
\end{array}
$$

$\theta_{3}, \theta_{4} \in \Re^{1} ; \theta_{1}^{\top}, \theta_{2}^{\top} \in \Re^{n-1}$ are constant parameters to be designed and $\Lambda(s)$ is an arbitrary monic Hurwitz polynomial of degree $n-1$ that contains $Z_{m}(s)$ as a factor, i.e.,

$$
\Lambda(s)=\Lambda_{0}(s) Z_{m}(s),
$$


which implies that $\Lambda_{0}(s)$ is monic, Hurwitz and of degree $n_{0}=n-1-q_{m}$. The controller parameter vector

$$
\boldsymbol{\theta}=\left[\begin{array}{llll}
\theta_{1}^{\top} & \theta_{2}^{\top} & \theta_{3} & \theta_{4}
\end{array}\right]^{\top} \in \Re^{2 n},
$$

is given so that the closed loop plant from $r$ to $y_{p}$ is equal to $W_{m}(s)$. The I/O properties of the closed-loop plant shown in Fig. 4 are described by the transfer function equation

$$
y_{p}=G_{c}(s) r
$$

where

$$
G_{c}(s)=\frac{k_{p} Z_{p} \Lambda^{2}}{\Lambda\left[\left(\theta_{4} \Lambda-\theta_{1}^{\top} \alpha\right) R_{p}-k_{p} Z_{p}\left(\theta_{2}^{\top} \alpha+\theta_{3} \Lambda\right)\right]},
$$

Now, the objective is to choose the controller gains so that the poles are stable and the closed-loop transfer function $G_{\mathcal{C}}(s)=W_{m}(s)$, i.e.,

$$
\frac{k_{p} Z_{p} \Lambda^{2}}{\Lambda\left[\left(\theta_{4} \Lambda-\theta_{1}^{\top} \alpha\right) R_{p}-k_{p} Z_{p}\left(\theta_{2}^{\top} \alpha+\theta_{3} \Lambda\right)\right]}=k_{m} \frac{Z_{m}}{R_{m}} .
$$

Thus, considering a system free of unmodeled dynamics, the plant coefficients can be known by the MRC structure, i.e., $k_{p}, Z_{p}(s)$ and $R_{p}(s)$ are given by 21 when the controller gains $\theta_{1}^{\top}$, $\theta_{2}^{\top}, \theta_{3}$ and $\theta_{4}$ are known and $W_{m}(s)$ is previously defined.

\section{Parameter identification using RMRAC}

The proposed parameter estimation method is executed in three steps, described as follows:

\subsection{First step: Convergence of controller gains vector}

The proposed parameter identification method is shown in Fig. 2. In this figure the parameter identification of $\mathrm{q}$ axis is shown, but the same procedure is performed for parameter identification of $\mathrm{d}$ axis, one procedure at a time.

A Persistent Excitant (PE) reference current $i_{s q}^{*}$ is applied at q axis of SPIM at standstill rotor. The current $i_{s q}$ is measured and controlled by the RMRAC structure while $i_{s d}$ stays at null value. The controller structure is detailed in Fig. 3 . When $e_{1}$ goes to zero, the controller gains go to an ideal value. Subsequently, the gradient algorithm is put in steady-state and the system looks like the MRC structure given by Fig. 4 . Therefore, the transfer function coefficients can be found using equation 21 .

\subsection{Second step: Estimation of $k_{p i}, h_{0 i}, a_{1 i}$ and $a_{0 i}$}

This step consists of the determination of the Linear-Time-Invariant (LTI) model of the induction motor. The machine is at standstill and the transfer functions given in 2 and 3 can be generalized as follows

$$
\frac{i_{s i}}{v_{s i}}=k_{p i} \frac{Z_{p i}(s)}{R_{p i}(s)}=k_{p i} \frac{s+h_{0 i}}{s^{2}+s a_{1 i}+a_{0 i}},
$$

where

$$
k_{p i}=\frac{L_{r i}}{\bar{\sigma}_{i}}, h_{0 i}=\frac{R_{r i}}{L_{r i}}, a_{1 i}=p_{i} \text { and } a_{0 i}=\frac{R_{s i} R_{r i}}{\bar{\sigma}_{i}}
$$


The reference model given by 5 is rewritten as

$$
W_{m}(s)=k_{m} \frac{Z_{m}}{R_{m}}=k_{m} \frac{s+z_{0}}{s^{2}+p_{1} s+p_{0}},
$$

and from the plant and reference model assumptions results

$$
\left\{\begin{array}{l}
m_{p}=1, n_{p}=2, n^{*}=1, \\
q_{m}=1, p_{m}=2, n_{m}^{*}=1,
\end{array}\right.
$$

The upper bound $n$ is chosen equal to $n_{p}$ because the plant model is considered well known and with $n=n_{p}$ only one solution is guaranteed for the controller gains. Thus, the filters are given by

$$
\left\{\begin{array}{l}
\Lambda(s)=Z_{m}(s)=s+z_{0} \\
\alpha(s)=z_{0}
\end{array}\right.
$$

Assuming the complete convergence of controller gains, the plant coefficients are obtained combining the equations 22,24 and 26 in 21 and are given by

$$
\left\{\begin{array}{l}
k_{p i}=k_{m} \theta_{4 i}, \\
h_{0 i}=\frac{z_{0}}{\theta_{4 \mathrm{i}}}\left(\theta_{4 i}-\theta_{1 i}^{\top}\right), \\
a_{1 i}=p_{1}+k_{m} \theta_{3 i}, \\
a_{0 i}=p_{0}+k_{m} z_{0}\left(\theta_{2 i}^{\top}+\theta_{3 i}\right) .
\end{array}\right.
$$

6.3 Third step: $R_{s i}, R_{r i}, L_{s i}, L_{r i}$ and $L_{m i}$ calculation

Combining the equations 4,23 and using the values obtained in 27 after the convergence of the controller gains, we obtain the parameters of the induction motor:

$$
\left\{\begin{array}{l}
\hat{R}_{s i}=\frac{a_{0 i}}{k_{p i} h_{0 i}}, \\
\hat{R}_{r i}=\frac{a_{1 i}}{k_{p i}}-\hat{R}_{s i}, \\
\hat{L}_{s i}=\hat{L}_{r i}=\frac{\hat{R}_{r i}}{h_{0 i}}, \\
\hat{L}_{m i}=\sqrt{\hat{L}_{s i}^{2}-\frac{\hat{R}_{s i} \hat{R}_{r i}}{a_{0 i}}} .
\end{array}\right.
$$

In the numerical solution it-is considered that stator and rotor inductances have the same values in each winding.

\section{Simulation results}

Simulations have been performed to evaluate the proposed method. The machine model given by 1 was discretized by Euller technique under frequency of $f_{s}=5 \mathrm{kHz}$. The SPIM was performed with a square wave reference of current and standstill rotor. The SPIM used is a four-pole, $368 \mathrm{~W}, 1610 \mathrm{rpm}, 220 \mathrm{~V} / 3.4 \mathrm{~A}$. The parameters of this motor obtained from classical no-load and locked rotor tests are given in Table 1. 


\begin{tabular}{|c|c|c|c|}
\hline$R_{s q}$ & $R_{r q}$ & $L_{m q}$ & $L_{s q}$ \\
\hline $7.00 \Omega$ & $12.26 \Omega$ & $0.2145 \mathrm{H}$ & $0.2459 \mathrm{H}$ \\
\hline$R_{s d}$ & $R_{r d}$ & $L_{m d}$ & $L_{s d}$ \\
\hline $20.63 \Omega$ & $28.01 \Omega$ & $0.3370 \mathrm{H}$ & $0.4264 \mathrm{H}$ \\
\hline
\end{tabular}

Table 1. Motor parameter obtained from classical tests.

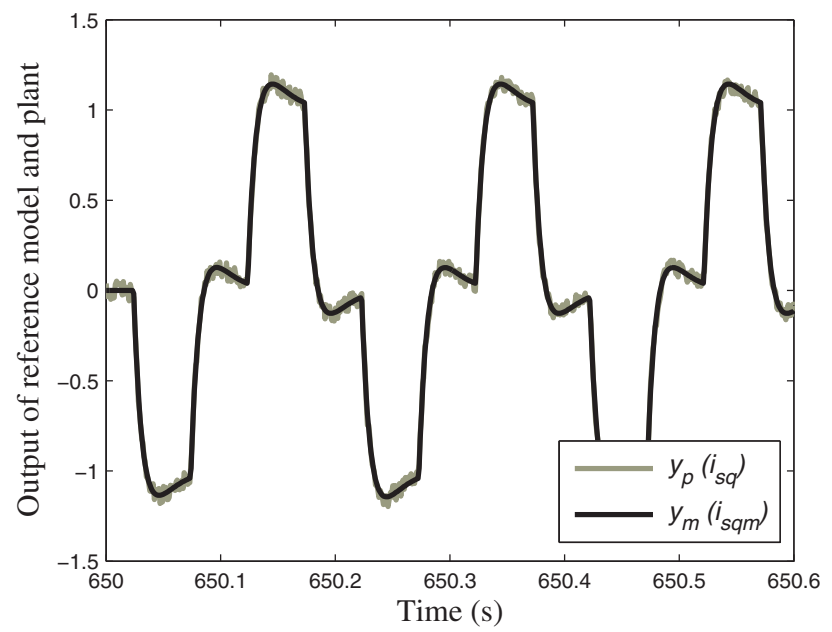

Fig. 5. Plant and reference model output.

The reference model $W_{m}(s)$ is chosen so that the dynamic will be faster than plant output $i_{s q}$. Thus, the reference model is given by

$$
W_{m}(s)=180 \frac{s+45}{s^{2}+180 s+8100},
$$

The induction motor is started in accordance with Fig. 2 with a Persistent Excitant reference current signal. A random noise was simulated to give nearly experimental conditions. Fig. 5 show the plant and reference model output after convergence of gains.

Fig. 6 shows the convergence of controller gains for parameter identification of $\mathrm{q}$ axis. This figure shows that gains reach a final value after 600s, demonstrating that parameter identification is possible. The gain convergence of $\mathrm{d}$ axis is shown in Fig. 7. Table 2 presents the final value of controller gains for the $q$ and $d$ axes, respectively.

\begin{tabular}{|c|c|c|c|}
\hline$\theta_{1 q}$ & $\theta_{2 q}$ & $\theta_{3 q}$ & $\theta_{4 q}$ \\
\hline-0.0096 & -1.0925 & 0.8332 & -0.0950 \\
\hline$\theta_{1 d}$ & $\theta_{2 d}$ & $\theta_{3 d}$ & $\theta_{4 d}$ \\
\hline-0.0164 & -0.6429 & 0.6885 & -0.0352 \\
\hline
\end{tabular}

Table 2. Final value of controller gains obtained in simulation.

The parameters of SPIM are obtained by combining the final value of controller gains from Table 2 with the equations 27, 28 and the reference model coefficients previously defined in 


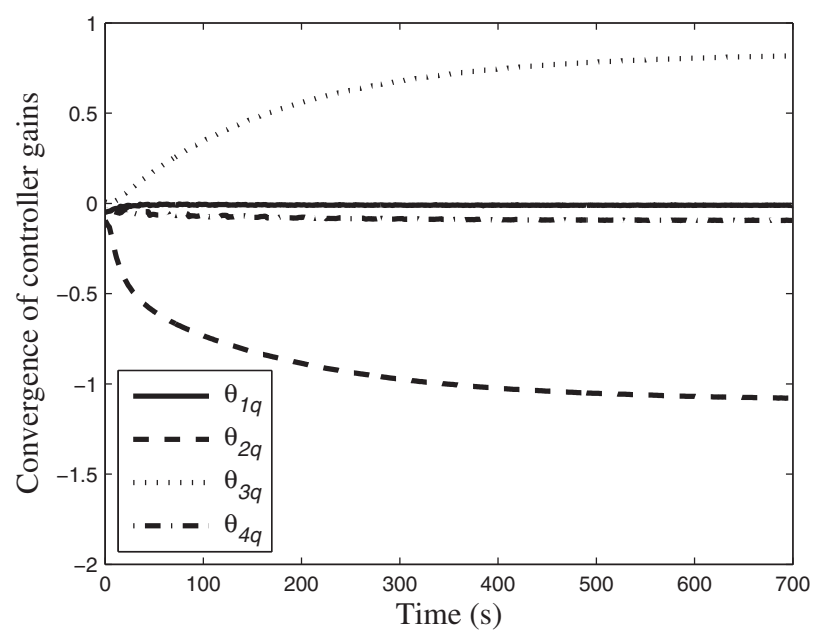

Fig. 6. Convergence of controller gains vector for q axis.

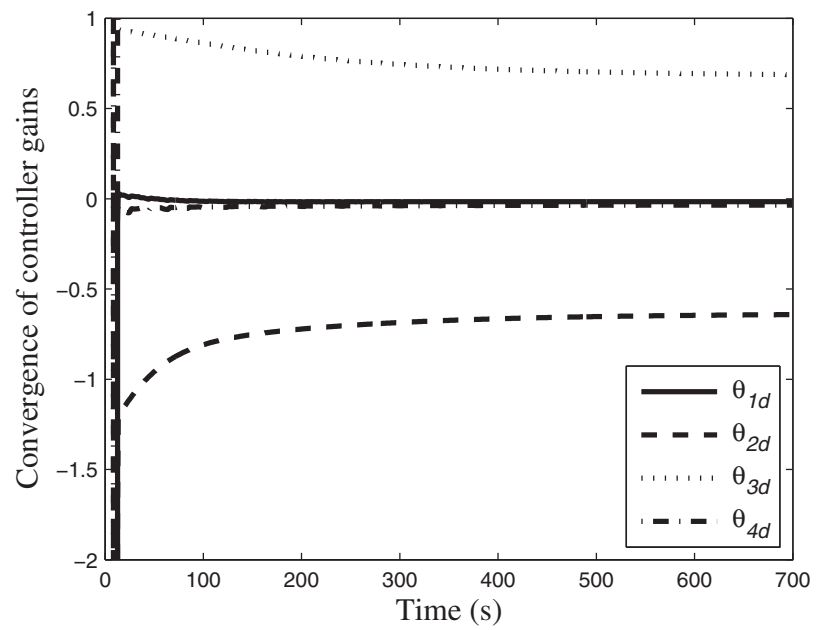

Fig. 7. Convergence of controller gains vector for $\mathrm{d}$ axis.

equation 29. The results are shown in Table 3. It is possible to observe in simulation that the electrical parameters converge to machine parameters, even with noise in the currents.

\begin{tabular}{|c|c|c|c|}
\hline$R_{s q}$ & $R_{r q}$ & $L_{m q}$ & $L_{s q}$ \\
\hline $7.07 \Omega$ & $12.21 \Omega$ & $0.2150 \mathrm{H}$ & $0.2462 \mathrm{H}$ \\
\hline$R_{s d}$ & $R_{r d}$ & $L_{m d}$ & $L_{s d}$ \\
\hline $20.22 \Omega$ & $27.67 \Omega$ & $0.3312 \mathrm{H}$ & $0.4292 \mathrm{H}$ \\
\hline
\end{tabular}

Table 3. Motor parameter identified in simulation. 


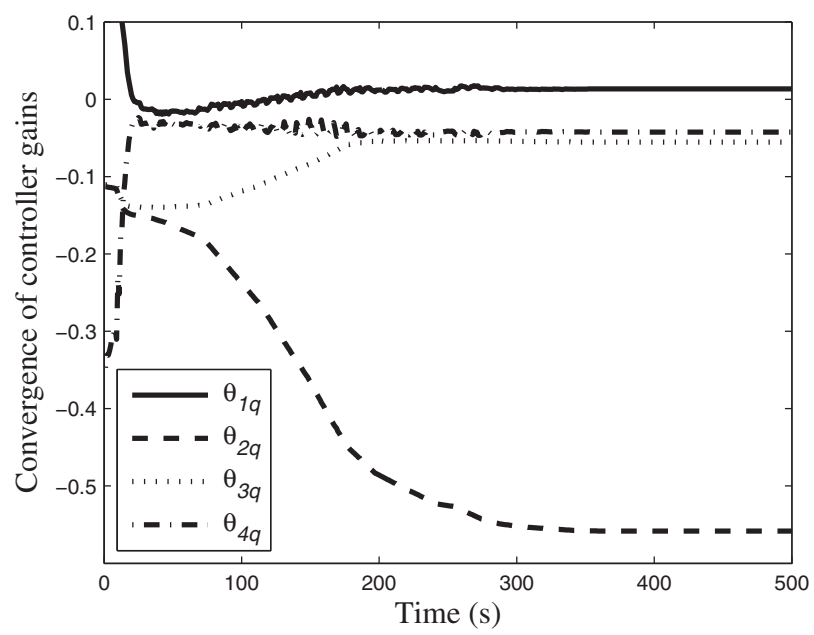

Fig. 8. Experimental convergence of controller gains for $\mathrm{q}$ axis.

\section{Experimental results}

This section presents experimental results obtained from the induction motor described in simulation, whose electrical parameters obtained by classical no-load and locked rotor tests are shown in Table 1. The drive system consists of a three-phase inverter controlled by a TMS320F2812 DSP controller. The sampling period is the same used in the preceding simulation.

Unlike the simulation, unmodeled dynamics by drive, sensors and filters, among others, are included in the implementation. This implies that the plant model is a little different from physical plant. As a result, there is a small error that is proportional to plant uncertainties and is defined here as a residual error. The tracking error $e_{1}$ can be minimized by increasing the gradient gain $\mathbf{P}$. However, increasing $\mathbf{P}$ in order to eliminate the residual error can cause divergence of controller gains and the system becomes unstable.

To overcome this problem a stopping condition was defined for the gain convergence. The identified stator resistance $\hat{R}_{s i}$ was compared to measured stator resistance $R_{s i}$ obtained from measurements. Thus, the gradient gain $\mathbf{P}$ must be adjusted until the identified stator resistance is equal to the stator resistance measurement.

Figure 8 presents the convergence of controller gains for $\mathrm{q}$ axis. The gains reach a final value after 400s. Figure 9 presents the convergence of controller gains for $d$ axis. The value of the gain that resulted in $\hat{R}_{s i}=R_{s i}$ was $\mathbf{P}=20 \mathbf{I}$.

The plant output $i_{s q}$ and reference model output $i_{s q m}$ are shown in Fig. 10, after controller gain convergence, where it is possible to see the residual error between the two curves. The final values of controller gains, for axes $\mathrm{q}$ and $\mathrm{d}$, are shown in Table 4.

The parameters of SPIM are obtained by combining the final value of controller gains of Table 4 with the equations 27, 28 and the reference model coefficients previously defined in equation 29. The results are shown in Table 5. 


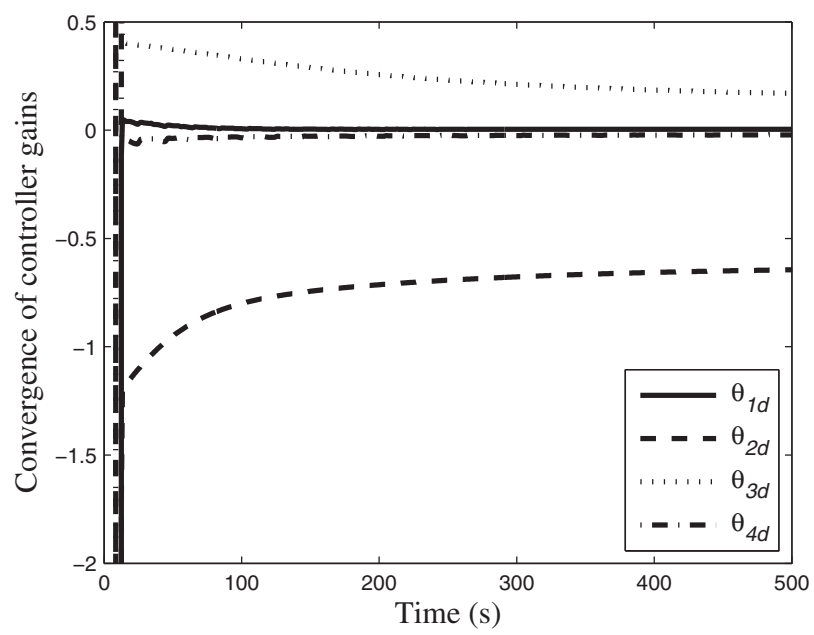

Fig. 9. Experimental convergence of controller gains for $\mathrm{d}$ axis.

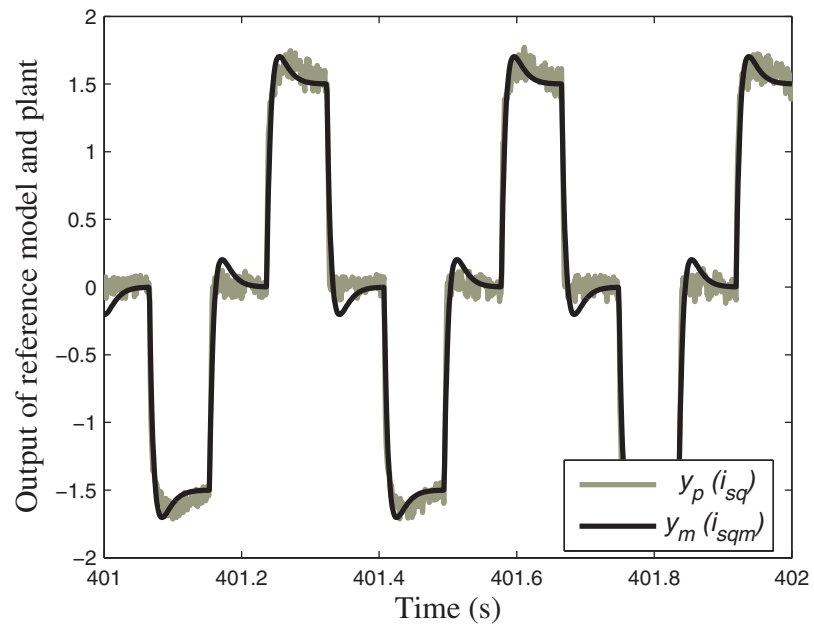

Fig. 10. Experimental plant and reference model output.

\begin{tabular}{|c|c|c|c|}
\hline$\theta_{1 q}$ & $\theta_{2 q}$ & $\theta_{3 q}$ & $\theta_{4 q}$ \\
\hline 0.0136 & -0.558 & -0.0555 & -0.0423 \\
\hline$\theta_{1 d}$ & $\theta_{2 d}$ & $\theta_{3 d}$ & $\theta_{4 d}$ \\
\hline 0.0042 & -0.6345 & 0.1560 & -0.0207 \\
\hline
\end{tabular}

Table 4. Final value of controller gains obtained in experimentation. 


\begin{tabular}{|c|c|c|c|}
\hline$R_{s q}$ & $R_{r q}$ & $L_{m q}$ & $L_{s q}$ \\
\hline $6.9105 \Omega$ & $15.4181 \Omega$ & $0.1821 \mathrm{H}$ & $0.2593 \mathrm{H}$ \\
\hline$R_{s d}$ & $R_{r d}$ & $L_{m d}$ & $L_{s d}$ \\
\hline $20.9438 \Omega$ & $34.9016 \Omega$ & $0.4926 \mathrm{H}$ & $0.6447 \mathrm{H}$ \\
\hline
\end{tabular}

Table 5. Motor parameter identified in experimentation.

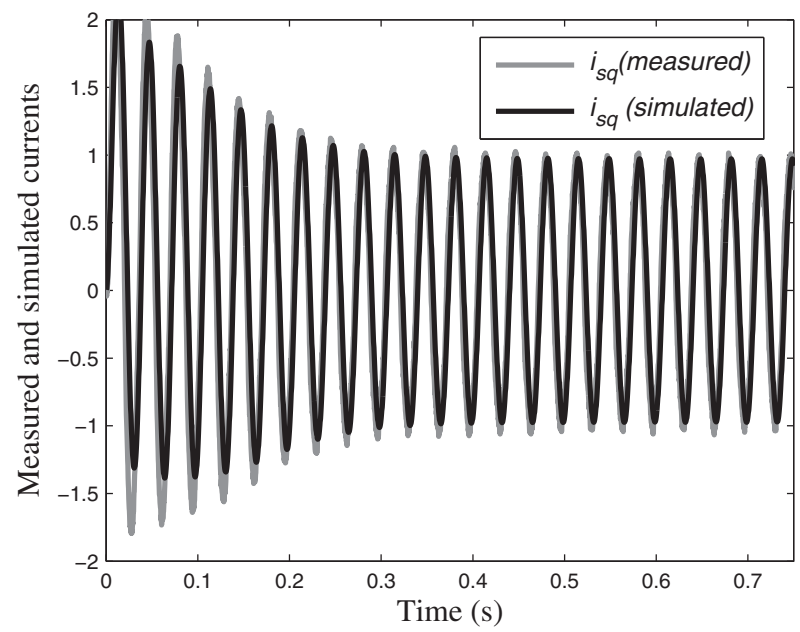

Fig. 11. Transient of comparison among measured and simulated currents from $q$ axis.

\subsection{Comparison for parameter validation}

A comparative study was performed to validate the parameters obtained by the proposed technique. The physical SPIM was fed by steps of $50 \mathrm{~V}$ and $30 \mathrm{~Hz}$. The currents of main winding, auxiliary winding and speed rotor were measured.

Then, the dynamic model of SPIM given by 1 was simulated, using the parameters from Table 5 , under the same conditions experimentally, i.e., steps of $50 \mathrm{~V}$ and $30 \mathrm{~Hz}$. The measured rotor speed was used in the simulation model to make it independent of mechanical parameters. Thus, the simulated currents, from $q$ and $d$ windings, were compared with measured currents. Figures 11 and 12 shows the transient currents from axis $q$ and d, respectively, while Figures 13 and 14 shows the steady-state currents from axis $q$ and $d$, respectively.

From Figures 11-14, it is clear that the simulated machine with the proposed parameters presents similar behavior to the physical machine, both in transient and steady-state.

\section{Conclusions}

This chapter describes a method for the determination of electrical parameters of single phase induction machines based on a RMRAC algorithm, which initially was used in three-phase induction motor estimation in (Azzolin \& Gründling, 2009). Using this methodology, it is possible to obtain all electrical parameters of SPIM for the simulation and design of an high performance control and sensorless SPIM drives. The main contribution of this proposed work is the development of automated method to obtain all electric parameters of the induction machines without the requirement of any previous test and derivative filters. Simulation 


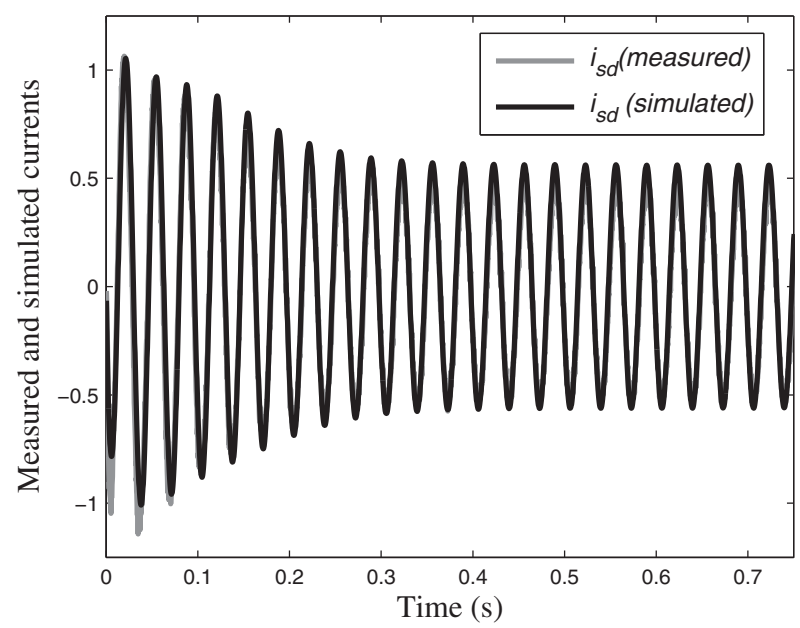

Fig. 12. Transient of comparison among measured and simulated currents from $\mathrm{d}$ axis.

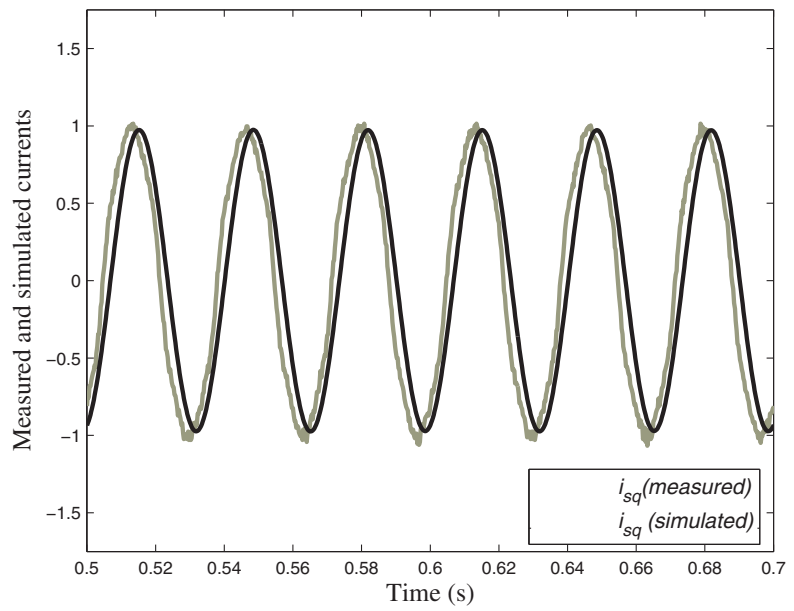

Fig. 13. Steady-state of comparison among measured and simulated currents from q axis.

results demonstrate the convergence of the parameters to ideal values, even in the presence of noise. Experimental results show that the parameters converge to different values in relation to the classical tests shown in Table 1. However, the results presented in Figures 11-14 show that the parameters obtained by proposed method present equivalent behavior to physical machine. 


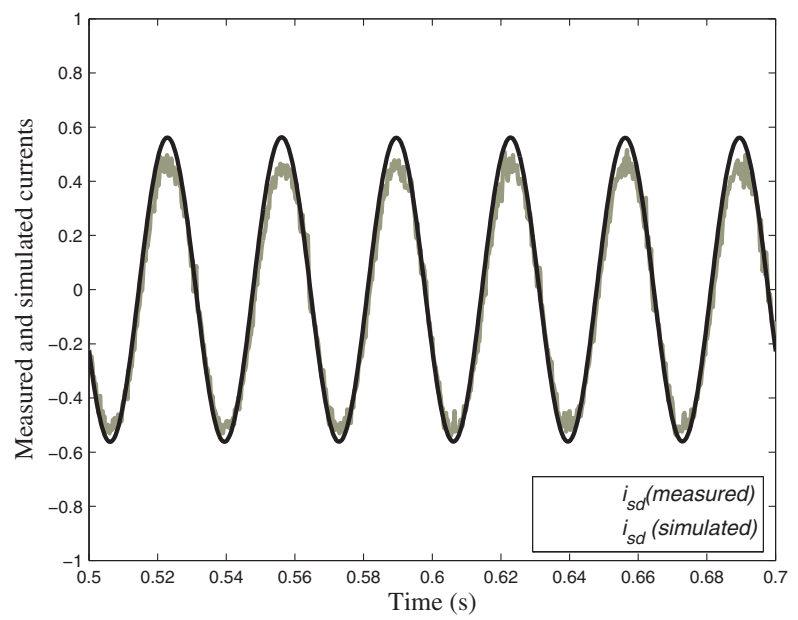

Fig. 14. Steady-state of comparison among measured and simulated currents from d axis.

\section{References}

Azzolin, R. \& Gründling, H. (2009). A mrac parameter identification algorithm for three-phase induction motors, Electric Machines and Drives Conference, 2009. IEMDC '09. IEEE International, pp. $273-278$.

Azzolin, R., Martins, M., Michels, L. \& Gründling, H. (2007). Parameter estimator of an induction motor at standstill, Industrial Electronics, 2009. IECON '09. 35th Annual Conference of IEEE, pp. $152-157$.

Blaabjerg, F., Lungeanu, F., Skaug, K. \& Tonnes, M. (2004). Two-phase induction motor drives, Industry Applications Magazine, IEEE 10(4): 24 - 32.

Câmara, H. \& Gründling, H. (2004). A rmrac applied to speed control of an induction motor without shaft encoder, Decision and Control, 2004. CDC. 43rd IEEE Conference on, Vol. 4, pp. 4429 - 4434 Vol.4.

de Rossiter Correa, M., Jacobina, C., Lima, A. \& da Silva, E. (2000). Rotor-flux-oriented control of a single-phase induction motor drive, Industrial Electronics, IEEE Transactions on 47(4): $832-841$.

Donlon, J., Achhammer, J., Iwamoto, H. \& Iwasaki, M. (2002). Power modules for appliance motor control, Industry Applications Magazine, IEEE 8(4): 26 -34.

Ioannou, P. \& Sun, J. (n.d.). Robust Adaptive Control, Prentice Hall.

Ioannou, P. \& Tsakalis, K. (1986). A robust direct adaptive controller, Automatic Control, IEEE Transactions on 31(11): $1033-1043$.

Koubaa, Y. (2004). Recursive identification of induction motor parameters, Simulation Modelling Practice and Theory 12(5): 363 - 381.

URL: http://www.sciencedirect.com/science/article/B6X3C-4CJVR4N-1/2/bcc4bdf719a9c7 ad5b99750423f5ff 23

Krause, P., Wasynczuk, O. \& Sudhoff, S. (n.d.). Analysis of Electric Machinery, NJ: IEEE Press. 
Lozano-Leal, R., Collado, J. \& Mondie, S. (1990). Model reference robust adaptive control without a priori knowledge of the high frequency gain, Automatic Control, IEEE Transactions on 35(1): $71-78$.

Ojo, O. \& Omozusi, O. (2001). Parameter estimation of single-phase induction machines, Industry Applications Conference, 2001. Thirty-Sixth IAS Annual Meeting. Conference Record of the 2001 IEEE.

Ribeiro, L., Jacobina, C. \& Lima, A. (1995). Dynamic estimation of the induction machine parameters and speed, Power Electronics Specialists Conference, 1995. PESC '95 Record., 26th Annual IEEE, Vol. 2, pp. $1281-1287$ vol.2.

Vaez-Zadeh, S. \& Reicy, S. (2005). Sensorless vector control of single-phase induction motor drives, Electrical Machines and Systems, 2005. ICEMS 2005. Proceedings of the Eighth International Conference on, Vol. 3, pp. 1838 -1842 Vol. 3.

Velez-Reyes, M., Minami, K. \& Verghese, G. (1989). Recursive speed and parameter estimation for induction machines, Industry Applications Society Annual Meeting, 1989., Conference Record of the 1989 IEEE, pp. 607 -611 vol.1.

Vieira, R., Azzolin, R. \& Gründling, H. (2009a). Parameter identification of a single-phase induction motor using rls algorithm, Power Electronics Conference, 2009. COBEP '09. Brazilian.

Vieira, R., Azzolin, R. \& Gründling, H. (2009b). A sensorless single-phase induction motor drive with a mrac controller, Industrial Electronics, 2009. IECON '09. 35th Annual Conference of IEEE, pp. $1003-1008$. 


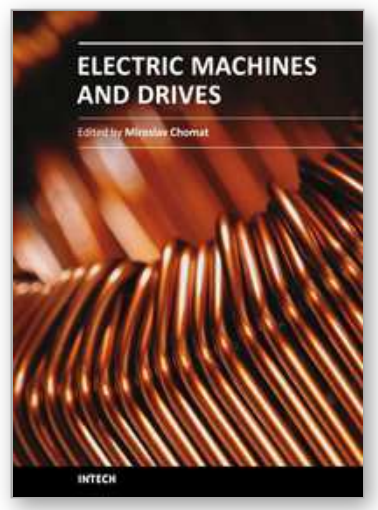

\author{
Electric Machines and Drives \\ Edited by Dr. Miroslav Chomat
}

ISBN 978-953-307-548-8

Hard cover, 262 pages

Publisher InTech

Published online 28, February, 2011

Published in print edition February, 2011

The subject of this book is an important and diverse field of electric machines and drives. The twelve chapters of the book written by renowned authors, both academics and practitioners, cover a large part of the field of electric machines and drives. Various types of electric machines, including three-phase and single-phase induction machines or doubly fed machines, are addressed. Most of the chapters focus on modern control methods of induction-machine drives, such as vector and direct torque control. Among others, the book addresses sensorless control techniques, modulation strategies, parameter identification, artificial intelligence, operation under harsh or failure conditions, and modelling of electric or magnetic quantities in electric machines. Several chapters give an insight into the problem of minimizing losses in electric machines and increasing the overall energy efficiency of electric drives.

\title{
How to reference
}

In order to correctly reference this scholarly work, feel free to copy and paste the following:

Rodrigo Z. Azzolin, Cristiane C. Gastaldini, Rodrigo P. Vieira and Hilton A. Gründling (2011). A RMRAC Parameter Identification Algorithm Applied to Induction Machines, Electric Machines and Drives, Dr. Miroslav Chomat (Ed.), ISBN: 978-953-307-548-8, InTech, Available from: http://www.intechopen.com/books/electricmachines-and-drives/a-rmrac-parameter-identification-algorithm-applied-to-induction-machines

\section{INTECH}

open science | open minds

\author{
InTech Europe \\ University Campus STeP Ri \\ Slavka Krautzeka 83/A \\ 51000 Rijeka, Croatia \\ Phone: +385 (51) 770447 \\ Fax: +385 (51) 686166 \\ www.intechopen.com
}

\author{
InTech China \\ Unit 405, Office Block, Hotel Equatorial Shanghai \\ No.65, Yan An Road (West), Shanghai, 200040, China \\ 中国上海市延安西路65号上海国际贵都大饭店办公楼 405 单元 \\ Phone: +86-21-62489820 \\ Fax: +86-21-62489821
}


(C) 2011 The Author(s). Licensee IntechOpen. This chapter is distributed under the terms of the Creative Commons Attribution-NonCommercialShareAlike-3.0 License, which permits use, distribution and reproduction for non-commercial purposes, provided the original is properly cited and derivative works building on this content are distributed under the same license. 